\title{
TEMA E IMAGEN EN SUPERCHERÍA. NAUFRAGIO EN GUADALAJARA
}

\author{
Mª Dolores DOBÓN \\ University of Virginia
}

Fuera de La Regenta y de Su único hijo podría argüirse que Superchería es la obra de ficción más importante de Clarín. En un profundo artículo, Nicholas Round ha señalado la riqueza temática de la obra. Round rechaza la tesis de Laura de los Ríos de que la obra trata esencialmente del conflicto "apariencia y realidad", la de Baquero Goyanes para quien la obra es, sobre todo, una "historia de amor", y la de G.G. Brown que la ve como un intento por parte de Clarín de ligar las memorias juveniles del protagonista, Nicolás Serrano, a un frustado amor de su madurez. Para Round el tema central de la novela consiste en el desarrollo moral de Serrano. Éste evoluciona desde la desorientación inicial que le ha convertido en un neurasténico, a la madura serenidad final que le permite, manteniendo su nuevo nivel moral, renunciar a un amor adúltero y encontrar en la renunciación el sosiego producido por la conciencia del deber cumplido ${ }^{1}$. El artículo de Nicholas Round está rigurosamente argüido y presentado con gran claridad; sin embargo, ese rigor expositivo y el énfasis en la unidad temática nos parece que restringe excesivamente la extraordinaria fecundidad intelectual de Superchería.

Como señala Mc.Bride, la escisión presentada por Clarín entre la infancia y la madurez, entre el niño Tomasucccio por una parte y por otra el filósofo escéptico de 30 años que protagoniza la novela (escisión señalada ya por Brown) es un tema capital ligado al contenido filosófico de la obra. Ese niño, apunta Mc.Bride, encarna la capacidad de visión religiosa y poética. Entre él y el filósofo neurasténico de la edad madura ha intervenido el estudiante racionalista que, al absorber las ciencias positivas de la época, mata al niño y engendra al escéptico. Al señalar la influencia de esta tesis de Superchería en la obra de

1. Nicholas Round expone y critica las tesis de Laura de los Ríos, y G.G. Brown en las pp. 97-98. Para la tesis de Round ver sobre todo las pp. 99, 102, 114, 116. 
Unamuno, Mc.Bride muestra no sólo su validez sino también su fecundidad ${ }^{2}$. En este artículo, intentaremos mostrar que tal fecundidad, ligada a la unidad esencial de la obra, es posible porque la estructura unitaria está regida por una polaridad dialéctica que reconcilia y trasciende el mundo poético religioso de la infancia con la visión racional del filósofo. Superchería es quizá una de las obras de Clarín en que éste ha utilizado más profundamente su excepcional don poético: mediante él Clarín enmarca esa oposición infancia-poética/madurezfilosófica en un contraste cielo/infierno que, como veremos, se resuelve mediante la intervención de una bruja angélica, en un amor que los integra.

Gonzalo Sobejano, con su habitual penetración, ha señalado ambos aspectos de Superchería: la multiplicidad de temas (que él denomina "acordes") y la unidad global dominante. Entre esos "acordes" señala Sobejano el tema religioso, expresado a través de la alucinación o visión de Santa Teresa, el del amor presentado a través de las relaciones de Nicolás Serrano con Caterina Porena, y el de la muerte que se refleja en las relaciones de Serrano con el niño Tomasuccio. Aun aceptando su tesis de que un tema importante de la obra, que unifica esos "acordes", es el de la relación conciencia-mundo, creemos que la tesis última de Superchería no se limita a plantearnos un problema de conocimiento, sino uno de amor y acción, y de un amor trascendente y redentor ${ }^{3}$.

Los distintos críticos arriba mencionados han coincidido en señalar la importancia del conflicto intelectual razón-fe en Nicolás Serrano; pero ¿qué características especiales posee un ansia de conocimento que hace de él simultáneamente una figura originalísima y una fuente de inspiracićn para sus compañeros del 98? Lo que lo constituye en un pensador único es la extraordinaria radicalidad de su pasión intelectual, que se convierte en una obsesión que lo lleva al borde de la locura. Nicolás Serrano es un caso de personalidad dividida entre una espiritualidad religiosa y un racionalismo exacerbado. Esa escisión no refleja simplemente una contradicción, sino una contradicción extrema: por una parte el hombre espiritual aspira, no ya a una fe religiosa, a una contemplación de realidades trascendendes, sino a la absoluta perfección espiritual. Clarín ha elegido para definirnos el ideal moral de Nicolás Serrano el modelo de vida perfecta propuesto por Jesús en el Evangelio: "Era rico; no necesitaba trabajar

2. Charles McBride sitúa Superchería en el contexto de las relaciones Unamuno-Clarín. Los documentos aportados por McBride no dejan lugar a dudas que Unamuno veía en Clarín a un precursor de sus propias inquietudes religiosas, en las que el maestro de Oviedo le influye poderosamente. Según McBride ambos luchan por salvarse de la nada y ambos han encontrado en la razón el obstáculo que les impide abrazar esa fe que su corazón anhela. El Nicolás Serrano de Superchería aparece, pues, no sólo como un precursor de Augusto Pérez sobre todo, y de otros héroes unamunianos, sino, como el mismo McBride señala, de los héroes del 98. Ver pág. 14. En cuanto a tal, es indudable que en Nicolás Scrrano encontramos un modelo del Antonio Azorín de La voluntad y del Fernando Ossorio de Camino de Perfección.

3. Nicholas Round y Gonzalo Sobejano se han preocupado de mostrar cómo la multiplicidad de subtemas está sometida a un tema primordial que los unifica: el desarrollo ético de Serrano en Round; la relación conciencia-mundo en Sobejano. El objeto de este artículo es evidentemente más limitado, e intento señalar un elemento temático fundamental, el contraste entre mundo ideal y mundo infernal, así como analizar las imágenes en las que esta distinción se expresa retóricamente. 
para comer, y aunque tenía el proyecto, ya muy antiguo en él, de dejarlo todo para los pobres y coger su cruz, esperaba, para poner en planta su propósito, tener la convicción absoluta, científica [...] de que semajante rasgo de abnegación estaba conforme con la justicia, y era lo que tocaba hacer" (Alas [1892] 1966, pág. 779a). Veamos, pues, que frente a ese radicalismo espiritual encontramos un análogo y opuesto radicalismo racional. Clarín señala desde el primer momento que el afán de comprender se ha convertido en Nicolás Serrano en una auténtica neurosis obsesiva: "cuanto le dice el médico lo ponía en tela de juicio". No quiere reconocer enfermedad alguna si no tiene de ella "clara conciencia". Hasta tal extremo llega la manía argumentativa que el narrador nos dice irónicamente que su médico lo manda tres años al extranjero "para con tal receta" verse libre de su enfermo. Clarín, sin embargo, no se limita a referirse a la monomanía racionalista de Nicolás Serrano con estas vagas alusiones irónicas; especifica muy precisamente en que consiste su racionalismo y cuáles son sus efectos patológicos. Se nos dice que Serrano ha aspirado "desde antiguo" a la perfección cristiana, pero para poder actuar necesita llegar "a una convicción absoluta, científica"; ahora bien, tal convicción supone una completa certeza a la que no puede llegar más que mediante la asimilación de la totalidad del conocimiento: "esta convicción dependía de todo un sistema; suponía multitud de verdades evidentes, metafísicas, físicas, antropológicas, sociológicas, religiosas y morales, averiguadas previamente" (Ibid, 779b).

Con Nicolás Serrano aparece en la ficción de fin de siglo el héroe abúlico, en el que la incapacidad para la acción nace de la aniquilación de la voluntad por una hipertrofia de la inteligencia. El hombre-reflexión ha matado al hombre-voluntad, y con él al niño soñador capaz de penetrar en el mundo del espíritu. Sin fe, Serrano se convierte en un desterrado de este mundo. El narrador resalta esa condición de exiliado; tras sufrir una profunda experiencia religiosa en el tren que le trae de Madrid, Clarín escribe:

En la emoción que sentía había la dulzura del dolor mitigado y espiritual, la impresión del destierro, el dejo picante de la austeridad del sentimiento religioso indeciso, pero profundo (Ibid, $781 \mathrm{~b}$ ).

¿Por qué es esa emoción dolorosa y dulce? Sin duda la dulzura se debe a su carácter religioso, y el dolor a que la razón ha establecido una barrera entre el anhelo espiritual de Serrano y el objeto trascendental al que el anhelo se dirige. La alusión al destierro espiritual sigue en el texto a la descripción de una experiencia mística que antecede y prepara la visión de Santa Teresa, que constituye uno de los motivos fundamentales de la novela. Siguiendo un tópico tradicional, la contemplación del cielo estrellado enciende en el espíritu de Nicolás Serrano un anhelo que resucita antiguas ansias religiosas, moviéndole a buscar en los astros luminosos una respuesta a las angustiosas inquietudes que lo agitan. En su visión nocturna, el cielo parece responder a su llamada enviándole como mensajero de la trascendencia al Espíritu Santo: 
La noche estaba serena; el cielo, estrellado [...] Las estrellas caían como una cascada sobre el horizonte, que parecía haberse hundido [...] Millares de estrellas titilaban [...] Un gran astro, cuya luz palpita, se le antoja paloma de fuego que batía muy lejos las luminosas alas, y del infinito venía hacia él, navegando por el negro espacio entre tantas islas brillantes (Ibid, 781 a).

Lo especialmente interesante de esta visión es que el narrador no se limite a describirnos esa llamada del mundo celestial, sino que, con intención maniquea, describe al mismo tiempo la tierra como el lugar infernal polarmente opuesto al luminoso espacio estelar. Mientras que las estrellas titilan en lo alto "la tierra, reprentada por la región de sombra compacta, parecía desvanecerse allá a lo lejos, cuesta abajo" (Ibid, 781a). Ese carácter de caída ("a lo lejos", "abajo") se repite a lo largo de la descripción: mientras que a luz de las estrellas cae sobre la tierra como una cascada, el horizonte terrestre "parecía haberse hundido". A la llamada celestial Nicolás responde con un impulso de elevación: "Nicolás, se complacía en figurarse que volaba por el espacio, lejos de la tierra" pero, desde la altura:

miraba a veces hacia el suelo y veía a la llama de los carbones encendidos que iba vomitando la locomotora como huellas del diablo; veía una mancha brusca de una peña pelada y parda que pasaba, rápida, cual arrojada al aire por la honda de algún gigante (Ibid, 781a).

La referencia al diablo remacha y clarifica la alusión a la llama de los carbones encendidos, clasificando la tierra como un mundo infernal. En este contexto la alusión a las peñas, obvia referencia al rocoso paisaje castellano, como armas arrojadas por hondas de gigantes, trae a la imaginación la clásica lucha de los titanes contra Dios, y consiguientemente junta el infierno griego con el cristiano. La conclusión del texto citado no deja lugar a duda de que la intención del autor es mostrar la oposición absoluta del mundo celestial a un mundo terrenal cuya desolación es el resultado del triundo de los poderes infernales:

[...] Bastábale ver el cielo tan grande, tan puro, tan lleno de mundos lejanos y luminosos; la tierra, tan humillada, desvaneciéndose en su sombra y sin más adorno que bruscas apariciones de tristes rocas esparcidas por el polvo acá y allá, como restos de una batalla de dioses (Ibid, 781b).

En este marco, tanto ideológico cuanto metafórico, tiene lugar la "aparición de Santa Teresa". Como sabemos, tal aparición desempeña una serie de funciones en el desarrollo temático y argumental de la novela, que han sido estudiadas con detenimiento por la crítica ${ }^{4}$. El fuerte efecto que la alucinación

4. Para Laura de los Rios esta "alucinación constituye la esencia misma de la novela, ya que es el instrumento narrativo por el que le autor presenta el tema de lo engañoso de las apariencias y de la dificultad de distinguir la realidad y la fantasía" (pp. 96-102). Round estudia este episodio como una de las cuatro fases esenciales para establecer la unidad narrativa de una historia, así como un episodio esencial para la interpretación del elemento temático que da título a la obra, es decir, la superchería (pp. 99, 109, 11 1). Para Gonzalo Sobejano el "suceso memorable" de la alucinación constituye el elemento fundamental del tema: "obsesión del intelectual por la trascendencia, incredulidad respecto al misterio, y final convencimiento de que la superchería no es el misterio que pueda subyacer a los fenómenos, sino éstos mismos" (pp. 96-97). 
le produce y que él anota en sus Memorias, leídas, mientras él duerme, por Caterina Porena, sirven de base para la sorprendente revelación que ésta lleva a cabo en la sesión de hipnotismo en casa del alcalde de Guadalajara, a que nos referimos más adelante. Tal sesión, como mostraremos, es un aquelarre, y los personajes que la dirigen son auténticas encarnaciones de fuerzas diabólicas.

La sesión de hipnotismo es un aquelarre porque Guadalajara representa ese mundo infernal que acabamos de encontrar en la experiencia mística antes analizada. Aun sin negar en modo alguno que la ciudad de Guadalajara connote alusiones autobiográficas de la propia adolescencia de Clarín, y que las referencias a las inquietudes literarias y sentimientos de la niñez y adolescencia de Serrano tengan también un cierto valor igualmente autobiográfico, tanto la ciudad cuanto dichas alusiones desempeñan una importante función temática. Guadalajara significa, literalmente, río de piedras ${ }^{5}$ : siguiendo de cerca la alusión a las rocas castellanas como instrumentos titánicos infernales, transformando metafóricamente las piedras en barro, la descripción que de ella hace Clarín no deja lugar a dudas de que ese mundo, en el que ahora entra Serrano, es un mundo excrementicio:

Llegó a la triste ciudad de Henares al empezar la noche, entre los pliegues de una nube que descargaba en hilos muy delgados y fríos el agua, que ya sucia corría sobre la tierra pegajosa (Ibid, 785a).

El texto, como vemos, es casi una traducción del nombre árabe; Serrano había vivido en Guadalajara seis meses a los doce o trece años, y este detalle biográfico sirve al narrador para hacer retroceder al protagonista, mediante el recuerdo, a sus años adolescentes. El recuerdo de su propia infancia sirve de enlace a su encuentro con el niño Tomasuccio, cuya inocencia y entusiasta espíritu poético en cierto modo parece identificado con el Serrano infantil. Al Ilegar a Guadalajara Serrano acude a una posada tan destartalada y miserable como la ciudad misma, y descubre que en ella se encuentra una pareja de farsantes (Vicenzo Foligno y Caterina Porena). En sus viajes los acompaña un inteligente y delicado niño, Tomasuccio. Inmediatamente después de llegar Serrano conversa con el niño, del que la criada de la fonda le dice que es el vivo retrato de la madre. La mención de la madre produce una sorprendente reacción en Serrano: se ve inmediatamente poseído de un furioso deseo de conocerla:

El deseo ardiente de verla fue para el filósofo de treinta años una voluptosidad intensa, como un día de verano al fin del otoño; la presencia de la juventud en el alma, cuando ya se la había despedido entre lágrimas disimuladas (Ibid, 790a).

Este retorno a la juventud hace que Serrano una el recuerdo de sus años juveniles con el presentimiento de una misteriosa afinidad con Caterina Porena; el mismo nombre lo seduce:

5. Guadalajara: [...] "el moro Rasís la llama Wadalfaxar aunque según D. Pascual Gayangos el verdadero que tuvo tras la invasión fue el de Medina-Alfarach ("ciudad de los barrancos" aludiendo a dos que la flanquean) si bien pronto tomó el del río cercano llamándose Wad-il-hachara o hachira (río de las piedras)". AA.VV., pág. 20. 
"Caterina Porena" [...] estas dos palabras [...] ahora tenían una extraña música sugestiva, algo de cifra babilónica; eran como el sésamo de nuevos misterios de la sensibilidad (Ibid, 790b).

La emoción misteriosa que cambia su otoño en verano le trae a la memoria un poema que escribió de adolescente, titulado El amante de la bruja. En su poema Serano se veía como un joven que, influído por Horacio, anhela:

[...] una visión a quien amar, una querida fiel en el sueño, la mágica Canidia aunque fuera, y el súcubo había acudido a su conjuro; más en vez de los torpes placeres del misterioso Cocytto, el adolescente había saboreado en los besos de la Canidia romántica el amor triste y profundo, ideal, caballeresco (Ibid, $790 \mathrm{~b})^{6}$.

El adolescente sueña que compartirá con el demonio esa bruja que se desdobla en ángel: cuando regrese "pálida, descarnada, palpitando aún como los últimos latidos de las eclampsias infernales del aquelarre mágico, besaba y abrazaba, llevada de amor puro, casto, ideal, a su pobre adolescente" (Ibid, $790 \mathrm{~b})$. Vemos, pues, que la amante soñada por el Serrano adolescente participa de la misma escisión maniquea que el súcubo amante del demonio: es, también, para el juvenil soñador, la casta esposa ideal. Como vamos a ver, esa bruja angélica soñada por Serrano en su adolescencia es una premonición de su futuro encuentro con Caterina Porena.

El mundo infernal de Superchería es Guadalajara, ese río de suciedad en el que tanto Nicolás Serrano como Caterina Porena son naúfragos. Caterina ha descendido a ese infierno fascinada por la atracción ejercida por Vicenzo Foligno, quien parece haberle robado el alma. El narrador insiste una y otra vez en que Foligno ha ejercido sobre ella una imperiosa fascinación: Foligno "cogió las manos de su mujer, y permanecieron, clavados los ojos, algunos minutos". La mirada de él ejerce sobre ella "cierto imperio de fascinación" (Ibid, 796b). Una y otra vez el texto refiere a Foligno como el "amo de Caterina" (Ibid, 796a). La actitud de ella es "sumisa y como vencida". Es indudable que ese poder ha arrastrado a Caterina al mundo infernal: "Lo que más le inquietaba era la indudable superioridad de Foligno, el domino de energía, y que en algún tiempo debía haber sido de seducción" (Ibid, 797a). Caterina era "una esclava que llora su servidumbre vergonzosa" (Ibid, 798a). Si Foligno aparece como poseyendo ese misterioso poder, el autor no deja lugar a duda de que Caterina, en cuanto su cómplice en ese mundo de superchería

6. Canidia: célebre maga y cortesana del tiempo de Augusto contra la que Horacio lanzó violentas diatribas (Épodos, 5 y 17; Sátiras 1 y 8) a causa de haberle negado sus favores, según se cree; la palinodia de la Oda I (XVI) se debe a la misma mujer. Según los escoliastas su verdadero nombre era Gratidia y había fabricado y vendido perfumes en Nápoles. La referencia al infierno clásico y a la bruja muestran que para Clarín el mundo excrementicio se identifica con el mundo infernal, y que Caterina Porena desempeña en él la función de bruja angelical que habíamos encontrado en el poema adolescente de Serrano. Descrita por Horacio, pues, Canidia es la bruja que arrastra al amante al mundo infernal (Cocytto). Claro está que Alas sobrepone a la figura infernal, la esclava de Foligno, la angelical que inspira a Serrano el amor ideal. 
hipnótica, es una bruja: Caterina es "cómica de lo maravilloso, histrionisa de las nuevas ciencias ocultas" (Ibid, 795a) y "su oficio es el de pitonisa moderna" (Ibid, 850a).

La novela se centra alrededor de un ritual infernal que corresponde al mencionado aquelarre, y que tiene lugar en casa del alcalde. El ritual consiste en un acto público en que éste quiere mostrar que también él posee fluido hipnótico. El narrador hábilmente insinúa el carácter religioso — de religiosidad demoníaca, por supuesto- del acto: "Había silencio como en un templo". Aunque sometida al imperio del esposo infernal, la auténtica ejecutora del ritual es Caterina Porena, al mismo tiempo sacerdotisa y víctima expiatoria, ya que si en cuanto bruja engaña a un auditorio con sus supercherías, en cuanto ángel, se somete a la trampa por amor a su hijo:

La Porena siempre en el éxtasis de su pena vivía como en un templo, sacerdotisa del dolor. Todo mal pensamiento era una profanación del altar en que se quemaba un corazón sacrificado al recuerdo de su hijo (Ibid, 809b).

El carácter sacrificial de la víctima, la caída de su alma pura en el mundo infernal, aparece metafóricamente descrita mediante la imagen de su muerte. Muerte de su espíritu, claro está: "[...] larga, rígida con los ojos cerrados. Parecía muerta y vestida para la caja". Bajo su cabello "de color de oro cubierto de ceniza" brilla su "frente ancha, pura y llena de dolor" (Ibid, 794b). Reúne el doble requisito de la mártir: la limpieza del oro y la pureza del espíritu aparecen cubiertos de la ceniza de la vergüenza y del dolor. El narrador, en estilo indirecto, nos describe la causa de ese dolor: "sintiendo, de fijo, la pena de la vergüenza de su papel grotesco en aquella sociedad de pobre necios" (Ibid, 795a).

Dijimos anteriormente que Caterina Porena había descubierto en el tren, leyendo las Memorias de Nicolás Serrano, que éste había creído tener una alucinación en que se le aparecía Santa Teresa. Cuando, en la sesión hipnótica, el protagonista hace público su escepticismo, Caterina le produce una terrible conmoción al adivinarle esa experiencia que, claro está, él cree totalmente secreta. Ese acto de adivinación, que confirma ante la audiencia el valor científico del hipnotismo y la fuerza del flujo hipnótico, es la superchería que da título a la obra. Y tal superchería corresponde al carácter mendaz de la ciencia moderna: ese fluido pretende darnos un poder sobre los hombres y la naturaleza que es falso. Nos ofrece una salvación basada en la mentira. Tal acto de superchería corresponde a la Caterina bruja. Frente al poder magnético de esa moderna pitonisa existe, sin embargo, otro poder que es auténticamente milagroso, y ese poder lo ejerce Caterina mediante un acto igualmente misterioso. En un determinado momento de la representación, Foligno hace que Caterina pueda descubrir la identidad de una persona por el simple contacto de un dedo puesto sobre su cabeza. Al apoyar Serrano su yema sobre ella la Porena "cogió su mano tibia y dulcemente suave la mano del filósofo". Serrano reacciona con misteriosa intensidad: 
Ya sabía él, por su lecturas y observaciones, que en el contacto hay misterios de afinidad y simpatía, revelaciones de la unidad cósmica $[. .$.$] pero$ nunca hubiera creído que una mano de mujer desconocida agarrándose a la suya con fuerza, sin verse las caras de ella y él, Caterina y Serrano, pudiera decir tantas cosas... Aquel contacto era un revelación evangélica del amor en el misterio (Ibid, 801b).

Frenta a la superchería hipnótica, ese contacto realizado fuera de la carne entre desconocidos, cerrados los ojos de ella, es un claro símbolo del amor espiritual que soñó el adolescente. Y ese amor sí es salvador: por él recibe Serrano una "revelación evangélica", es un amor misterioso y que, como nos había indicado el poema del adolescente, nos abre la puerta hacia un mundo "profundo, ideal, caballeresco". El texto nos muestra que ese amor, para ellos imposible, es el del hogar, el del matrimonio, la maternidad y la paternidad, que permiten que el ser humano realice, en esta existencia guadalajariana, una imagen del mundo ideal trascendente?

El análisis de las relaciones de Caterina con Tomasuccio, de Tomasuccio con el Babbo (abuelo), y de ambos con Serrano, requeriría un nuevo y amplio estudio. En éste nos proponíamos mostrar como, dentro de la serie de temas y subtemas que componen la armónica estructura de esta novela, existe uno que, dominándola y enlazándolos, nos comunica la impresionante y original visión de Clarín. En Superchería se nos presenta la existencia terrenal en un mundo sin Dios como dominada por poderes demoníacos. El hombre o la mujer espiritual, que aspira a un amor ideal y noble, es, según palabras de su autor, un naúfrago en ese río de fango de la Guadalajara simbólica. La ciencia que ha reemplazado a la fe es una superchería. Existe, sin embargo, una fuerza misteriosa, evangélica, que trasciende la ciencia y que nos abre el camino a la vida del espíritu, que nos eleva hacia ese pájaro de luz que desciende de las estrellas. Al comunicarnos, a oscuras, con la bruja angélica, con la mujer amante y maternal, escapamos de los poderes demoníacos. El previo matrimonio de Caterina Porena impide que los naúfragos puedan realizar su amor ideal; pero, como indica Nicholas Round, esa salvación no ha sido en vano. El enfermo psíquico-moral que era el antiguo Nicolás Serrano ha engendrado un nuevo hombre - moralmente íntegro y personalmente completo- al que su nueva elevación moral dota de fortaleza y dignidad.

7. El tema del hogar, del amor matrimonial, y del hijo como huella en la tierra del ideal religioso, ha sido ampliamente estudiado por Francisco García Sarriá en su libro Clarín o la herejía amorosa. En el contexto de nuestro estudio, la relación entre Serrano, Caterina Porena, y Tomasuccio apunta hacia aquel amor, puramente espiritual, por el que el ser humano puede escapar del mundo infernal. El hecho de que tanto Nicolás Serrano como Bonifacio Reyes (el protagonista de Su único hijo) no sean los padres naturales del hijo nos muestra que la idealidad es el elemento que da carácter redentor a ese amor conyugal. García Sarriá nos ha indicado cómo el modelo religioso de esa paternidad es la Encarnación (pp. 198-190). El Tomasuccio en cuanto hijo representa, pues, la influencia moral que, como el hijo de Emma y Bonifacio en Su único hijo, eleva y transforma moralmente a Serrano: "En consonancia con este plano (el histórico social) existe otro moral-religioso que es el más profundo y el que más importa a Clarín [...] Bonifacio busca en el hijo-Jesús la seguridad de que existe un Dios que le es necesario para ordenar su conducta moral" (pág. 188). 


\section{BIBLIOGRAFÍA}

AA.VV. 1942. Historia de Guadalajara y sus Mendozas en los siglos XV y XVI, Madrid, Consejo Superior de Investigaciones Científicas.

ALAS, Leopoldo. [1892] 1966. Obras Selectas, Madrid, Biblioteca Nueva.

BROWN, G.G. 1964. "Introduction to Leopoldo Alas", en Cuentos escogidos, Oxford, Dolphin Book Co.

DE LOS RÍOS, Laura. 1965. "Superchería. Apariencia y realidad", en Los cuentos de Clarín: proyección de una vida, Madrid, Revista de Occidente, págs. 91-112.

GARCÍA SARRIÁ, Francisco. 1975. Clarín o la herejía amorosa, Madrid, Gredos.

McBRIDE, Charles. 1969. "Afinidades espirituales y estilísticas entre Unamuno y Clarín", en Cuadernos de la Cátedra Miguel de Unamuno, XIX, págs. 5-37.

ROUND, Nicholas G. 1970. "The fictional integrity of Leopoldo Alas. Superchería", Bulletin of Hispanic Studies, XLVII, 2, págs. 97-116.

SOBEJANO, Gonzalo. 1985. "Leopoldo Alas; maestro de la novela corta y el cuento", en Clarín en su novela ejemplar, Madrid, Castalia, págs. 77-114. 